\section{Estratégias para comunicação de diagnóstico de HIV a parceiros sexuais e práticas de saúde}

\author{
Strategies for disclosing HIV status to sexual \\ partners and their relationship to healthcare \\ provision
}

\author{
${ }_{1}^{1}$ Prefeitura do Município de \\ São Paulo, São Paulo, Brasil. \\ 2 Faculdade de Medicina, \\ Universidade de São Paulo, \\ São Paulo, Brasil. \\ Correspondência \\ N. E. K. Silva \\ Prefeitura do Município de \\ São Paulo. \\ Rua Voluntários da Pátria 4130 , \\ apto. 124-B, São Paulo, SP \\ 02402-500, Brasil. \\ neks@usp.br
}

\begin{abstract}
Disclosure of HIV status to sexual partners poses a challenge during healthcare provision, highlighting both the responsibility for controlling the epidemic and ensuring the patient's psychosocial well-being. This study's objective was to grasp the strategies used by health professionals for such disclosure. This is a qualitative study based on the discourse of health professionals and patients at specialized STD/AIDS clinics in the city of São Paulo, Brazil, using individual interviews and focus and educational groups. The strategies range from threatening to complicity, and the main focus is to minimize the stigma attached to individuals with HIV. It is believed that an active problem-solving approach to stigma in real situations in the clinic can provide a possible and practical path for dealing with such stigma, by creating argumentative repertoires, allowing the emergence of normative horizons that are technically, ethically, and politically relevant for integrating disclosure of the HIV diagnosis to the sexual partner and healthcare for persons with HIV.
\end{abstract}

Acquired Immunodeficiency Syndrome; HIV; Sexual Partners; Diagnosis
Neide Emy Kurokawa e Silva 1

José Ricardo de Carvalho Mesquita Ayres 2

\section{Introdução}

Contrastando com os debates e investimentos em países como os Estados Unidos 1,2,3,4, no Brasil, a questão da comunicação de diagnóstico de HIV a parceiros sexuais de pessoas vivendo com HIV/AIDS não tem merecido grande visibilidade na área da saúde, e os Manuais de Controle de Doenças Sexualmente Transmissíveis contêm apenas menções esparsas ao assunto 5,6.

$O$ fato de não ter destaque em iniciativas oficiais não significa que a temática não seja alvo de preocupações, de dúvidas ou de intervenções, sobretudo dos profissionais de saúde que lidam cotidianamente com situações em que o paciente se nega a comunicar seu status sorológico aos parceiros sexuais ou não consegue fazê-lo. Movidos tanto por sua responsabilidade pública com o controle da cadeia de transmissão do HIV quanto pela sua responsabilidade privada com o bem-estar psicossocial do paciente em suas relações afetivo-sexuais, conjugais e familiares, os profissionais de saúde têm necessidade, de alguma forma, de adotar estratégias para que os parceiros sexuais de pessoas vivendo com HIV/AIDS tomem ciência da situação.

O presente trabalho tem como objetivo específico apreender, com base nos discursos de profissionais de saúde e de pessoas vivendo com HIV/AIDS, as estratégias de comunicação do diagnóstico a parceiros sexuais utilizadas nos serviços de saúde. 


\section{Metodologia}

Trata-se de estudo qualitativo 7 , baseado na apreensão de discursos de profissionais e pacientes de serviços de saúde especializados em DST/AIDS, do Município de São Paulo (Tabelas 1 e 2). O critério de escolha desse campo foi o interesse em acessar serviços que, de um lado, contassem com suficiente experiência no assunto especificamente estudado e, de outro lado, tivessem suas práticas e fundamentos menos estruturados que serviços universitários e centros de referência. O material empírico foi coletado no período de 2007 a 2008 e o seu conteúdo foi gravado e transcrito.

Os discursos dos profissionais de saúde foram captados por meio de um grupo focal ${ }^{8} \mathrm{e}$ de entrevistas individuais em profundidade, a partir de roteiro semi-estruturado, contando com trabalhadores das seguintes áreas: educação em saúde, enfermagem, fonoaudiologia, medicina, psicologia, serviço social, terapia ocupacional, nutrição. O recurso a essas técnicas pareceu apropriado para obter tanto discursos oriundos de experiências individuais, quanto aqueles que emergem do debate em torno do tema, expressando tanto as singularidades das experiências quanto as dinâmicas comunicativas que conformam o referido debate $?$.

Os serviços especializados em DST/AIDS do Município de São Paulo apresentam relativa homogeneidade quanto à composição da equipe, serviços oferecidos, histórico de criação e de formação dos profissionais no trabalho com pessoas vivendo com HIV/AIDS. Por isso, tanto para a participação nos grupos focais quanto nas entrevistas, não se recorreu a qualquer tipo de seleção a priori entre eles.

O convite para integrar o grupo focal foi feito a todas as unidades da rede de serviços municipais especializados em HIV/AIDS, por intermédio de profissionais formalmente designados pela Secretaria Municipal de Saúde de São Paulo (SMS-SP) como interlocutores entre pesquisadores e suas unidades. Atenderam voluntariamente à chamada nove profissionais oriundos de cinco serviços de diferentes regiões da cidade, entre os 15 que compõem a rede assistencial.

Por facilidades de acesso para a pesquisa, e considerada a homogeneidade dos serviços, as entrevistas individuais se concentraram em duas unidades de uma única região da cidade, envolvendo 11 profissionais de saúde.

O número total de participantes das entrevistas individuais não foi estipulado a priori, sendo definido ao longo do processo de pesquisa, segundo critério de suficiência, isto é, quando do julgamento de que o material empírico permitiria traçar um quadro compreensivo da questão investigada. A preocupação central foi focalizar o tema da comunicação de diagnóstico de HIV a parceiros sexuais sob várias perspectivas e pontos de vista, permitindo não só certa reincidência das informações como também aquelas consideradas ímpares 7 .

$\mathrm{O}$ acesso aos discursos dos pacientes dos serviços foi feito pela observação de duas sessões de um grupo educativo, dirigido a mulheres vivendo com HIV/AIDS, tendo como objetivo discutir a comunicação da infecção a parceiros sexuais, presentes, passados e potenciais.

Ao identificar que algumas pacientes tinham dificuldade de compartilhar a informação sobre sua infecção com seus parceiros sexuais, uma médica ginecologista decidiu convidar algumas delas para debater a questão, apostando na fecundidade da troca de experiências. A profissional foi uma das depoentes da investigação e, sensibilizada com a sua temática, fez o convite para que a atividade fosse observada pela pesquisadora.

Tabela 1

Perfil das participantes do grupo educativo.

\begin{tabular}{|c|c|c|c|c|c|c|}
\hline \multirow[t]{2}{*}{ Nome } & \multirow{2}{*}{$\begin{array}{c}\text { Data de } \\
\text { nascimento }\end{array}$} & \multirow{2}{*}{$\begin{array}{c}\text { Ano do } \\
\text { diagnóstico }\end{array}$} & \multirow[t]{2}{*}{ Profissão } & \multicolumn{2}{|c|}{ Parceiros } & \multirow{2}{*}{$\begin{array}{l}\text { Revelado } \\
\text { Sim/Não }\end{array}$} \\
\hline & & & & Sim/Não & Status/HIV & \\
\hline Januaria & 09/Fev/1964 & 2006 & Empregada doméstica & Sim & $?$ & Não \\
\hline Cristina & 28/Nov/1957 & 2004 & Do lar & Sim & $\mathrm{HIV}+$ & Sim \\
\hline Madalena & 02/Set/1966 & 2005 & Analista de crédito & Não & - & - \\
\hline Greta & 12/Jul/1967 & 2002 & Balconista & Sim & $?$ & Não \\
\hline Baía & 31/Out/1959 & 2004 & Professora & Não & - & - \\
\hline Monique & 10/Jun/1945 & 1996 & Advogada & Não & - & - \\
\hline
\end{tabular}


Tabela 2

Profissionais de saúde, por estratégia utilizada.

\begin{tabular}{|c|c|}
\hline \multicolumn{2}{|c|}{ Entrevistas em profundidade } \\
\hline Nome & Formação/Profissão \\
\hline \multicolumn{2}{|l|}{ Campo A } \\
\hline Clara & Médica \\
\hline Miguel & Médico \\
\hline Lia & Assistente Social \\
\hline Irene & Psicóloga \\
\hline Bebel & Médica \\
\hline Carolina & Enfermeira \\
\hline Bárbara & Médica \\
\hline \multicolumn{2}{|l|}{ Campo B } \\
\hline Silvia & Educadora em Saúde Pública \\
\hline Olívia & Psicóloga \\
\hline Fernando & Médico \\
\hline Luiza & Assistente Social \\
\hline \multicolumn{2}{|l|}{ Grupo focal } \\
\hline Nome & Formação/Profissão \\
\hline Maria & Fonoaudióloga \\
\hline Bebel & Médica \\
\hline Chico & Médico/Estudante \\
\hline Adelaide & Nutricionista \\
\hline Lourival & Terapeuta Ocupacional \\
\hline Marieta & Médica/Professora \\
\hline Elza & Enfermeira \\
\hline Anne & Psicóloga \\
\hline Bethania & Fisioterapeuta \\
\hline
\end{tabular}

Foram convidadas dez mulheres, com experiências bem e mal sucedidas de revelação, das quais compareceram seis. O processo, desenvolvido em duas sessões, foi coordenado pela médica e por uma psicóloga.

O material produzido nas entrevistas e grupos focais recebeu um tratamento hermenêutico 7 , vale dizer, foi trabalhado de modo compreensivo/interpretativo, buscando-se identificar eixos de significação organizadores dos discursos acerca dos fatos, ações, valores, crenças e sentimentos relacionados às experiências práticas em relação à comunicação de diagnóstico de HIV a parcerias sexuais.

Para orientar essa hermenêutica, recorreu-se ao quadro conceitual da Teoria da Ação Comunicativa ${ }^{9}$, tendo como eixos organizadores centrais a distinção entre os sentidos comunicativo e estratégico dos atos de fala. São entendidos, aqui, os discursos como linguagem em ato, como proferimentos lingüísticos que expressam sempre alguma pretensão de validade intersubjetiva, que se procurou identificar e interpretar nas falas dos depoentes.

Dos nexos entre a ação e a linguagem, entre o agir e o falar, Habermas 10 ressalta o aspecto pragmático da linguagem, ou seja, o uso que os sujeitos fazem dela, como forma de interação. Segundo essa perspectiva, toda ação humana é baseada num modo de se posicionar no mundo, num modo de estar no mundo, e este é sempre lingüisticamente mediado. Por isso, o modo como a linguagem se conforma nos diversos discursos nos dá acesso ao modo como se organizam as ações humanas.

Habermas recorre à moderna filosofia da linguagem (Apel e outros) e à teoria dos atos lingüísticos ("speech acts", de Austin e outros) para postular a existência de três tipos básicos de atos de fala nos discursos: (a) locucionário: expressa um estado de coisas; (b) ilocucionário: realiza uma ação enquanto se diz algo; e (c) perlocucionário: causa um efeito sobre o ouvinte, produz algo no mundo.

Da distinção entre atos de fala de tipo ilocucionário e de tipo perlocucionário, Habermas divide os tipos de interação discursiva, respectivamente, em ação comunicativa, na qual predomina o interesse do falante na busca de entendimento com seu interlocutor; e a ação de tipo teleológico, em que prevalece no falante o objetivo de produzir algum efeito ou reação no ouvinte.

Assim, na ação comunicativa, o falante procura se entender a respeito de algo com um ouvinte, formulando asserções acerca do mundo objetivo, das normas sociais ou das suas experiências pessoais, diante das quais o interlocutor toma uma posição com um "sim" ou um "não" a respeito da validade do que está sendo afirmado, isto é, da sua veracidade, sua correção (ética, política, moral) ou sua autenticidade, respectivamente 10 .

Em contraste com a ação comunicativa, a ação estratégica é orientada a fins predeterminados, estando em jogo a influência dos atores uns sobre os outros, pelo recurso a ameaças, gratificações, sugestões ou enganos 10 .

Lembrando que a distinção entre ação comunicativa e estratégica é apenas um recurso para a apreensão interpretativa dos discursos, posto que raramente as ações sociais se apresentam como absoluta e exclusivamente comunicativas ou instrumentais 11, é possível, com base na Teoria da Ação Comunicativa, interpretarmos não apenas o sentido predominante do interesse de um discurso (comunicacional ou estratégico), como também conteúdos das experiências e identidades sociais e pessoais dos seus sujeitos (aspectos proposicionais, normativos e expressivos da validade postulada por discursos). 
O presente estudo foi aprovado pela Comissão de Ética para Análise de Projeto de Pesquisa da Diretoria Clínica do Hospital das Clínicas e da Faculdade de Medicina da Universidade de São Paulo em 14 de fevereiro de 2007 (protocolo de pesquisa $n^{\circ}$. 1347/06) e pelo Comitê de Ética em Pesquisa da SMS-SP, em 6 de fevereiro de 2007 (parecer $n^{\circ}$. 0029/2007). Foram obtidos consentimentos pós-informados de todos os informantes, sendo tomados os cuidados éticos quanto ao sigilo e à privacidade das informações colhidas.

\section{Resultados e discussão}

Uma expressão, proferida por um dos depoentes, revela a preocupação dos profissionais com suas responsabilidades em relação aos parceiros sexuais não cientes de suas exposições ao HIV: "nem omissão, nem invasão”. Eles assumem o dever de tomar alguma iniciativa quando os pacientes não conseguem, não querem ou não podem comunicar seus diagnósticos aos parceiros.

Esse dever é tomado pelos profissionais sob diferentes perspectivas, que transitam entre a necessidade de regras ou normas e o respeito à autonomia e liberdade do paciente quanto à comunicação do diagnóstico de HIV aos respectivos parceiros sexuais.

Foi possível perscrutar essa polarização ao indagar os informantes sobre a possibilidade do Brasil vir a incorporar a Notificação de Parceiros - um recurso da Vigilância Epidemiológica, com regras bem definidas, baseado na busca de comunicantes e largamente utilizado nos Estados Unidos 12,13. Uma primeira reação foi de rejeição: "Esse sistema [Notificação de Parceiros] funciona na Alemanha, na Suiça porque são alemães, são suíços. Aqui no Brasil, não funciona!" (Maria).

De um lado, esse ceticismo ancora-se nas bases culturais para a implementação de uma proposta dessa natureza e não necessariamente no seu conteúdo ou nos seus pressupostos.

"Você falou dessa experiência dos Estados Unidos. Eles vão em cima, eles investigam, eles comunicam todos os parceiros. Eu acho que deveria ser assim. Mas eu acho que aqui no Brasil é difícil fazer isso. O brasileiro é meio desconfiado. Ele leva as coisas muito no pessoal. Ele não tem esse espírito de sociedade. Esse espírito coletivo. É muito individualista. Por incrível que pareça! (...) ele pensa no quintal dele. Ele não tá nem aí pro vizinho (...) Eu acho que aqui no Brasil é difícil fazer isso. Eu acho que é impossível. Acho que isso não vai acontecer" (Miguel).

De outro, questiona-se o sentido ético mesmo da prática, chamando a atenção para as dife- rentes responsabilidades envolvidas na situação de comunicação de diagnóstico: "Se isso [Notificação de Parceiros] for implantado aqui, vai acontecer o que já acontece. Vamos nos livrar do peso da angústia, com esses casos que a gente não consegue conduzir; a gente vai se livrar da dor de carregar essa situação. Vai transferir a responsabilidade pra outra autoridade (...) a gente pode falar da lei e mostrar uma oportunidade dele falar assim, assim, assim. Não do jeito absoluto: ou dá ou desce! Nada pode ser assim" (Elza).

Considerando o ímpeto de se tomar alguma iniciativa com relação aos parceiros sexuais e o ceticismo quanto à idéia de se circunscrever a responsabilidade pela saúde coletiva a uma estratégia como a notificação compulsória de parceiros, os profissionais elegem ações centradas no próprio paciente, para que ele promova a comunicação do diagnóstico.

"Eu acho que o elo de ligação entre o profissional e a terceira pessoa é o paciente! Não posso chegar a essa terceira pessoa, não sendo através do meu paciente. Eu acredito que seja muita invasão da intimidade (...) Você tem que chegar a essa terceira pessoa, através da paciente. Acho que não tem outro caminho" (Bebel).

Assim, a partir do momento em que tomam conhecimento de que a condição sorológica para o HIV não foi comunicada aos parceiros, os profissionais têm como medida geral aconselhar os pacientes a fazê-lo. A recusa em revelar ou a omissão sobre a situação sorológica ao parceiro sexual repousa sob vários contextos e os profissionais, embora possam acolher e se compadecer dessa dificuldade, raramente abrem mão da prerrogativa de insistir na necessidade de que o parceiro seja informado da situação.

Sob o quadro da Teoria da Ação Comunicativa, deslindamos as estratégias para lidar com a revelação de diagnóstico de HIV aos parceiros sexuais, segundo gradações de perspectivas: daquelas com enfoques mais objetivadores, orientados primordialmente pelo êxito técnico, no caso, concretizado na revelação do diagnóstico e na suposição de que, assim procedendo, a cadeia de transmissão do HIV será interrompida, até aquelas que mais se aproximam da busca de um entendimento, por meio do fluxo de processos argumentativos e da interação.

Nesse sentido, para fins analíticos, construímos uma tipologia, a seguir detalhada, para identificar as estratégias acionadas pelos profissionais de saúde, ressaltando que elas não se apresentaram isoladamente, entrelaçando-se e indicando a presença de múltiplas normatividades nas abordagens dos profissionais. 


\section{Ameaça: a exclusividade da finalidade técnica}

Uma das estratégias mais drásticas, do ponto de vista da inexistência da busca de soluções compartilhadas, é a ameaça, entendida como um modo de tentar coagir o paciente a revelar o seu diagnóstico, anunciando possíveis sanções, caso essa comunicação não seja feita.

Via de regra, a ameaça tem muito mais o intuito de intimidar o paciente, como mais um recurso para forçá-lo a revelar a situação ao parceiro, do que propriamente a intenção de cumpri-la.

O conteúdo das ameaças refere-se tanto à comunicação ao parceiro, mesmo que à revelia do paciente, quanto a supostas implicações legais e judiciais da não revelação.

Esse recurso é utilizado diante do julgamento que o profissional faz do caso e do paciente, e algumas situações parecem servir como argumentos incontestáveis para o uso da ameaça, como aquelas envolvendo crianças em risco de serem infectadas. Ao saber, por intermédio da esposa de um paciente, que ele teve um filho de uma união extraconjugal, cuja parceira desconhecia a sua situação sorológica, uma profissional teve a iniciativa de abordá-lo nos seguintes termos:

"Eu soube que você teve um filho há vinte dias. 'É, eu tenho!'. Então, como já estamos no avançar da noite, 6 horas da tarde, eu vou ser bem clara com você: você precisa contar para essa moça que você tem AIDS, trazer aqui, porque senão você pode ser processado! Isso é homicídio doloso! Teve a intenção de contaminar! Depois de meia hora tava ele, a mulher e a criança! (...) Ele fez sob pressão. Se foi bem sucedido, não sei, mas a criança está salva!" (Anne).

A pressuposição de que o paciente estaria deliberadamente colocando "uma vítima inocente" - a criança - em risco, justificou o recurso à ameaça, baseada em um único argumento, da promessa de uma sanção, que obrigaria o paciente a revelar sua condição sorológica para o HIV à parceira sexual. A ameaça tem por finalidade influenciar o paciente para que ele tome iniciativas, em acordo com a expectativa do profissional, evidenciando o seu caráter predominantemente estratégico.

Ao ter como mote um fim específico, que é a comunicação do diagnóstico de HIV ao parceiro sexual, a estratégia da ameaça pode interditar a emergência e fluxo de outros argumentos, quer do próprio profissional, quer do paciente.

\section{Campanha: a centralidade da finalidade técnica}

Ao tomarem conhecimento de que um paciente não comunicou seu parceiro sobre o diagnóstico de HIV, os profissionais de saúde passam a investir, cada um a seu modo, em discursos para dissuadir esse paciente da manutenção do segredo. Vislumbra-se a dimensão desse esforço e dessa insistência se nos reportarmos ao sentido da palavra campanha, como um processo maciço de persuasão: "a gente acaba sabendo de muitos casos em que a pessoa não revelou e daí começa a campanha" (Olivia).

"A gente fica em cima. Quando a gente sabe que não contou, a gente fica em cima pra contar!" (Luiza).

O que estamos nomeando como campanha seria um processo envolvendo dois ou mais membros da equipe em torno de um caso específico de não revelação, com o intuito de ampliar os conteúdos dos discursos, além dos seus locutores individuais, a fim de convencer o paciente na questão da comunicação do seu diagnóstico ao parceiro.

Assume-se coletivamente o problema, embora tomado na parcialidade do trabalho de cada profissional, sem que haja uma articulação entre os saberes e fazeres de cada um dos trabalhadores envolvidos com o caso. Na verdade, reproduzse aqui um fenômeno observado não apenas em relação à revelação do diagnóstico, mas ao manejo multiprofissional dos casos nos serviços de saúde em geral 14,15.

"Eles acabam mandando pro Serviço Social e pra Psicologia mesmo! Mesmo os médicos, pra gente lidar com o problema (...) Às vezes o pessoal tá chorando lá embaixo, eles mandam pro Serviço de Psicologia. Eu falei: 'chorou, vai conversar com o psicólogo!' Eles esperam que pare de chorar ou espera que resolva o problema" (Olivia).

Não sendo nosso foco discutir especificamente as expectativas e configurações da equipe para a questão da comunicação do diagnóstico, cabe pontuar o movimento presenciado, de se ampliar o repertório argumentativo, ao contar com mais de um profissional na tarefa de fazer com que o paciente consiga comunicar seu diagnóstico de HIV ao parceiro sexual.

A justificativa para a estratégia da campanha pode ser depreendida em um depoimento no qual o profissional explica a insistência, mesmo que à primeira vista seus argumentos não causem a reação esperada por parte do interlocutor.

"Você faz sempre a mesma coisa, sempre. Você fica explicando: não faça isso, não faça aquilo! Mas sem o compromisso de conseguir aquilo! Antes eu ficava preocupado, eu me frustrava por não conseguir essa mudança no paciente. Hoje eu consigo lidar melhor com isso. Mas continuo insistindo pra largar o cigarro, pra fazer dieta, pra entrar numa academia. A gente tem que estar sempre falando. Antes eu desistia. E hoje em dia, 
não! Você dá a mesma atenção pra todo mundo. Você tem que continuar fazendo a coisa certa, independentemente do resultado que você vai conseguir" (Miguel).

De modo similar à estratégia da ameaça, a campanha situa a finalidade estratégica de um modo ainda bastante apartado de um sentido propriamente comunicacional na interação com os pacientes. De todo modo, amplia-se claramente o repertório de argumentos para além da intimidação do paciente, buscando-se validar o comportamento proposto, isto é, a revelação ao parceiro, em argumentos de diferentes naturezas, de modo a convencer racionalmente o paciente.

\section{Conselho: a finalidade técnica ampliada}

Se na modalidade anterior participavam do cenário da ação a equipe e o paciente, nessa estratégia, que denominamos conselho, a relação direta entre profissional e paciente se faz mais presente e intensa. Aqui, a interação produz um ativo esforço interpessoal com intuito de solucionar o problema da revelação, atravessado por racionalidades e afetos de ordem não estratégica.

"Eu tenho vários casos de menina que são soropositivas e arrumam namorados que não são e perguntam assim: 'eu devo avisar?' Eu falo: Não, espera! Deixa aprofundar o relacionamento, né, e depois faz a revelação. Porque senão você pode nunca ter a chance de ter alguém!" (Clara).

A depoente analisa a situação relacionando a finalidade da comunicação do diagnóstico a outras, como a proteção das pacientes contra o estigma relacionado à infecção pelo HIV, o que muda o enfoque do tempo para a revelação. Nesse exemplo, a comunicação é contextualizada, na tentativa de defender a paciente das possíveis conseqüências negativas dessa revelação.

Os conselhos também são marcados por máximas em torno das relações conjugais, que contrastam amor/afeto com as reações diante da revelação do diagnóstico de HIV ao parceiro.

Pressupõe-se, nesse contexto, que quem ama não abandona: "Eu pergunto pra ela se ela gosta realmente do parceiro. Se ela gosta, ela vai querer cuidar daquela pessoa. E pra cuidar daquela pessoa, ela tem que ser honesta na relação. Eu tento passar essa informação de que aquela pessoa, rompendo o relacionamento, talvez não seja tão boa quanto ela imaginava, né? A pessoa que gosta de mim, ela vai gostar de mim em qualquer situação. Então, se aquela pessoa rompeu o relacionamento só por ela ter HIV, seria até mais um indício de que aquela pessoa não gostava dela (...) Os pacientes? Ah, eles aceitam, eles concordam com isso!" (Miguel).
Vemos, portanto, que o conselho, sem perder de vista a finalidade técnica de controlar a cadeia de transmissão do HIV, parece considerar outros critérios de sucesso para as intervenções em saúde.

\section{A cumplicidade: a experiência (inter)pessoal como recurso técnico}

Na mesma linha da abordagem denominada conselho, que se movimenta na moldura mais restrita da relação interpessoal entre profissional e paciente, podemos identificar outra estratégia, que denominamos cumplicidade. Ela se manifesta tanto quando o profissional se oferece para participar do processo de comunicação, ou mesmo responsabilizar-se pela sua realização, quanto no compartilhamento de um "teatro" visando criar condições favoráveis para que ela seja feita.

Um exemplo de participação no processo de comunicação diz respeito à história de um paciente que não conseguia revelar seu status sorológico à esposa, temendo que ela o abandonasse. A enfermeira, conhecendo sua dificuldade e com o assentimento do paciente, procedeu à comunicação. A seguir registramos o seu relato, em entrevista individual, sobre a conversa com o paciente e sua esposa.

Enfermeira: "Olha, deixa eu falar uma coisa pra você. O Fulano falou pra mim que teve um tempo preso, né? E esse tempo que ele esteve preso, você teve algum relacionamento? Aí ela falou que teve. Lá na Bahia ela teve outra pessoa. Aí eu falei: Olha, eu vou falar um coisa pra você, que eu já havia comentado com o seu marido e eu pedi para que ele trouxesse hoje você aqui. E ele a trouxe hoje. Eu acho que ofato de ele ter trazido você aqui já é uma prova de que ele te ama. Ele fez o exame, né, e o exame dele deu um HIV positivo. Falei se ela sabia que ele estivera preso, ela falou que sabia, foi por isso que ela tinha ido pro norte. Ela ficou parada na cadeira".

Esposa: "Eu não acredito! Por que que ele não me falou, ele tá tendo relação comigo sem preservativo!".

Enfermeira: "Olha, você já deve ter ouvido falar que hoje, uma das maiores vítimas da infecção é a mulher. E a mulher, mesmo casada, ela deve usar preservativo. Quer dizer, se porventura você estiver infectada, você também não pode se revoltar contra ele. Primeiro, que você sabe que ele teve uma história e que esteve preso. Outra, que você nem imagina se você também está infectada. Porque você também teve outro relacionamento. No outro relacionamento você usou preservativo?".

Esposa: “Não usei!".

Enfermeira: "Não falei que ele tinha desde 96, né? Falei que era uma coisa que ele tinha feito ago- 
ra. Olha, então, ele tá infectado, você também não pode julgar porque você não sabe se você também está infectada e se você se infectou com outro relacionamento. Quer dizer, se ele errou, você também errou. Porque você também deveria estar usando preservativo. Hoje é um chamado, a mídia, tudo fala que tem que usar preservativo. Então você também não pode culpá-lo. O fato dele ter trazido você aqui é uma prova de amor também. Porque ele poderia ter desaparecido daqui" (Carolina).

$\mathrm{O}$ relato acima nos elucida muitos aspectos em relação ao vínculo da profissional com o paciente, a partir do qual a enfermeira, ao assumir sua cumplicidade com o paciente, concentra todos os esforços argumentativos para neutralizar qualquer sentimento de culpabilização ou vitimização que pudesse produzir efeitos negativos sobre a relação conjugal, tanto quanto sobre a não proteção da infecção pelo HIV.

Nesse relato a cumplicidade também envolve a profissional no que chamamos de teatro, ou seja, ela "administra" a informação sobre o tempo de diagnóstico do paciente, a favor desse.

Outra dimensão da cumplicidade como teatro foi garimpada em depoimentos que nos dão conta de novas situações em que a chamada "administração" das informações sobre o diagnóstico do paciente é ativamente incorporada ao teatro: "Ela conheceu uma pessoa, casou, engravidou... Antes da gravidez eu tinha conversado com ela a respeito de contar pro companheiro dela. Ela não queria, não queria... aí ela engravidou. O nosso receio era que ela abandonasse o pré-natal, por conta de estar sendo pressionada a contar para o parceiro. No fim, ela acabou contando, com a ajuda da equipe. Ela contou. Como se ela tivesse sabido na gestação, mas ela já sabia antes, né? É muito dificil porque a gente tem a responsabilidade do outro, que tem que ser preservado e tem tambémo próprio usuário. Fica difícil!" (Lia).

Ainda sugerindo certa dramatização, não foram raras as referências à frase: "e se fosse você" para que o paciente se coloque no lugar do parceiro e perceba o quanto gostaria de ser cientificado sobre o status sorológico do companheiro e dele próprio.

“Eu peço pra pessoa, assim, imaginar-se no lugar dela, se o parceiro que ela teve no passado a contaminou, se ele tivesse falado pra ela, ela não teria essa doença, pra ela se colocar no lugar do outro. Porque o outro tá na situação que ela viveu! Ela poderia ter evitado essa situação se o parceiro tivesse comunicado o diagnóstico pra ela. Se ele soubesse também! Nunca vai saber se a pessoa omitiu essa informação ou se a pessoa também desconhecia. Mas eu tento pedir pra ela fazer esse exercício. De se imaginar no lugar da outra" (Miguel).
As mudanças de perspectivas - do profissional no lugar do paciente; do paciente que adota a perspectiva do parceiro - permitem ou pelo menos buscam facilitar o jogo argumentativo a fim de validar os discursos dos profissionais com o recurso à dimensão mais afetivo-subjetiva da relação com o outro e da experiência da infecção pelo HIV.

Identificamos ainda uma outra estratégia de lidar com a comunicação do diagnóstico com recurso às experiências pessoais e à presença do outro, desta feita na experiência com o grupo de mulheres organizado para discutir especificamente a questão.

\section{Grupo de discussão: alteridade e comunicação no mundo da técnica}

Essa modalidade circunscreveu-se a um caso pontual, de desenvolvimento de um grupo educativo, cuja concepção foi relatada por sua idealizadora, uma das depoentes das entrevistas individuais, que atua em um dos serviços investigados. Além do seu depoimento, foi possível observar o processo grupal, que passou a integrar o material empírico da investigação.

A profissional justifica a criação do grupo: "A proposta que eu estou fazendo agora é de juntar pessoas que tenham problemas semelhantes, mas posturas diferentes. Se a gente consegue aprender pelo exemplo é melhor do que pelo sofrimento. E também, assim, as histórias de vida são diferentes. Os problemas são semelhantes. Então quando a gente percebe que as pessoas também têm sofrimento e vê como ela pode lidar com aquele sofrimento, você tem mais subsídios, mais exemplos para colocar na sua memória, para ver como as pessoas resolvem os seus problemas" (Barbara).

A expectativa da profissional é, portanto, enriquecer o repertório argumentativo das mulheres com dificuldades para fazer a revelação aos seus parceiros, por meio da explicitação das experiências, temores e expectativas.

Considerando que algumas delas nem sequer almejavam ter um companheiro, temendo o momento de informar seus status sorológicos, uma das estratégias propostas para o grupo foi a dramatização de situações envolvendo a comunicação do diagnóstico, o que pode ser observado no próprio processo grupal.

Durante as duas sessões que foram observadas as mulheres enfatizaram o receio de sofrerem rejeição ou preconceito dos parceiros, caso revelassem suas condições sorológicas e, portanto, sustentavam a impossibilidade de fazê-lo.

A dramatização, com uso de cenas como recurso técnico para o grupo trabalhar experiên- 
cias concretas da situação em foco, explorando os sentidos práticos, afetos e valores relacionados 16 , foi proposta na segunda sessão, tendo como consigna a história de uma mulher sabidamente infectada pelo HIV (M.) que conheceu um homem (P.) e depois de três meses, quando o relacionamento parecia estreitar-se, ela resolveu falar sobre a sua situação sorológica ao parceiro.

A seguir relatamos os diálogos que compuseram as três cenas propostas.

- Cena 1: envolvendo duas mulheres do grupo, no papel de M. e P.

M.: "Estamos juntos há um tempo... tenho uma coisa pra te falar".

P.: "Pode falar. O que foi?".

M.: "Eu sou soropositiva!".

P.: "O quê? Como você não me disse antes? Olha, eu gostei muito de você, mas não estou preparado!".

M.: "Você sabe como pega? Não gostaria de saber mais?".

P.: "Sei, mas não vai dar!".

M.: "Eu compreendo. Tudo bem. Podemos ser amigos?".

- Cena 2: envolvendo uma mulher do grupo e a psicóloga, nos papéis de M. e P., respectivamente.
M.: "Eu tenho uma coisa pra te contar!".
P.: 'Fala, M.!".
M.: "Eu sou portadora do HIV há 7 anos".
P.: “Que bom que você me contou!".

- Cena 3: envolvendo duas mulheres do grupo, nos papéis de M. e P.

M.: "Eu quero contar uma coisa. Eu sou soropositiva!".

P.: "Você não poderia ter feito isso comigo! [reação violenta]".

M.: "Mas não houve nada entre nós, portanto, não houve risco!".

P.: “[nervoso] Eu vou processá-la!”.

M.: "[com dificuldade, trêmula] Eu é que vou processá-lo! Por discriminação!”.

Pode-se dizer que, no grupo observado, não obstante o interesse estratégico da comunicação do diagnóstico ser ainda o norte da atividade, logrou-se alcançar um tratamento discursivo de uma natureza que se aproxima de uma ação comunicativa na acepção habermasiana, na medida em que diversas perspectivas subjetivas puderam ser levantadas e examinadas nas diferentes pretensões de validade que permeavam seus respectivos discursos. Assim, a comunicação do diagnóstico foi tratada não como um objetivo técnico a ser alcançado de um modo já dado, mas como um desafio prático para aquelas pessoas, configurado pelos diversos modos de entender e se posicionar diante da infecção, de si mesmo e do outro.

Outro importante elemento na experiência do grupo estudado foi a emergência, na Cena 3, de uma surpreendente transformação do lugar do sujeito que revela sua infecção ao parceiro: da desvalorização e opressão à potente condição de um sujeito de direitos. Dois aspectos são especialmente instigantes nessa passagem. O primeiro é a evidência do potencial que um encontro efetivamente comunicacional apresenta para o enriquecimento de alternativas para lidar com situações complexas de atenção à saúde, como aqueles que discutimos no presente trabalho. $\mathrm{O}$ segundo é a demonstração de como uma mesma situação prática analisada desde um horizonte normativo diverso - da necessidade epidemiológica de controle da epidemia ao imperativo ético-político de proteção dos Direitos Humanos - pode descortinar para os sujeitos diferentes possibilidades de manejo da situação.

\section{A gestão do estigma e o cuidado: considerações finais}

A par do esforço para que suas ações consigam dar conta da dupla responsabilidade - com o "outro", supostamente em risco de ser infectado pelo HIV, e com o paciente e seus contextos de vida -, os profissionais buscam soluções recorrendo a discursos que, embora tensionados pelos imperativos técnicos de controle da transmissão do vírus, procuram considerar as particularidades de cada situação.

$\mathrm{O}$ que vimos, antes de qualquer coisa, foi a diversidade das estratégias adotadas frente a essas tensões e particularidades, com os méritos e dificuldades de cada uma delas. Porém, a análise do material vai também deixando patente, e completamente explícito na última situação discutida, que o determinante central das tensões entre as finalidades igualmente válidas e necessárias de impedir a disseminação da infecção pelo HIV e proteger o bem-estar pessoal e social das pessoas vivendo com o HIV é o processo de estigmatização do portador do vírus.

Parker \& Aggleton 17, tomando como ponto de partida o trabalho clássico de Goffman 18, chamam a atenção para uma versão comum do estigma que, como um "atributo depreciativo", pode ser equivocadamente tomado desde uma perspectiva "naturalizada". Enfatizam que o processo de estigmatização não é individual ou algo que certos indivíduos fazem a outros; não são produzidos no vácuo, mas são produtos de contextos de cultura e de poder. 
Mesmo não sendo argüidos diretamente sobre o estigma, os profissionais demarcaram reiteradamente essa questão e sua presença é intuída nos modos como conduzem suas práticas em torno da questão dos comunicantes sexuais, desencadeando o que poderia ser chamado de gestão do estigma.

O estigma relacionado à infecção pelo HIV pode, como vimos, ser ignorado ou encarado como um fator incidental, que não deve obstar as ações de comunicação a parceiros sexuais. Mas mesmo as atitudes de gestão do estigma podem precipitar iniciativas de tutela do paciente, o que acaba excluindo-o do processo ou mesmo tornando o problema invisível da mesma forma.

Vimos, por outro lado, que uma experiência de discussão que ampliou sua tônica, da transmissão do vírus para outros aspectos envolvendo a conjugabilidade, foi capaz de produzir o trânsito de um discurso vitimizador para outro, que ressaltou a condição de sujeito, capaz de argumentar e defender seus pontos de vista.

Nesse ponto, cabe retomar as indicações iniciais de que as estratégias não se configuram como tipos puros de intervenções, mas como possibilidades, acionados na dependência de contextos, circunstâncias e particularidades de cada caso.

\section{Resumo}

A comunicação de diagnóstico de HIV a parceiros sexuais representa um desafio às práticas de saúde e evidenciam tanto a responsabilidade com o controle da epidemia quanto com o bem-estar psicossocial do paciente. O objetivo do estudo é apreender as estratégias utilizadas pelos profissionais de saúde para a realização da comunicação. Trata-se de estudo qualitativo baseado nos discursos de profissionais de saúde e pacientes de serviços especializados em DST/AIDS do Município de São Paulo, Brasil, com entrevistas individuais e grupos focal e educativo. Oscila-se entre estratégias de ameaça e de cumplicidade e o principal foco é minimizar o estigma que cerca o portador do vírus. Vislumbra-se que a ativa problematização do estigma nas situações concretas da atenção pode ser um caminho possível e prático para o seu enfrentamento, por meio da criação de repertórios argumentativos, possibilitando a emergência de horizontes normativos técnica, ética e politicamente relevantes para integrar comunicação de diagnóstico de HIV ao parceiro sexual e atenção à saúde das pessoas vivendo com HIV.

Sídrome de Immunodeficiência Adquirida; HIV; Parceiros Sexuais; Diagnóstico
Se temos a tarefa técnica de controle da epidemia de AIDS, é fundamental que ela não prescinda da mútua compreensão e participação de todos os sujeitos envolvidos em tal desafio. Nesse aspecto, recorremos à noção de cuidado 19 , que nos remete à importância de se conciliar qualquer compromisso de êxito técnico em saúde com as efetivas possibilidades práticas de seu alcance, definidas pelas razões e afetos por que se movem os sujeitos em seus contextos sociais. Isto implica fundir horizontes entre os diversos sujeitos envolvidos, buscando resgatar, para além do caráter instrumental de nossos saberes e de nosso fazer, e por seu intermédio, as possibilidades comunicativas inscritas nas diversas ações de saúde.

O exame das estratégias acima elencadas indica a relevância de se investir na construção (e reconstrução) de repertórios argumentativos que ampliem as possibilidades de diálogo entre profissionais e pacientes, acerca dos parceiros sexuais e da comunicação de diagnóstico de HIV, superando a idéia do caráter irremediavelmente conflituoso entre o interesse da saúde pública e o interesse pessoal do paciente e a suposta necessidade de sacrificar este em benefício daquele.

\section{Colaboradores}

N. E. K. Silva elaborou e realizou o estudo e redigiu o artigo. J. R. C. M. Ayres orientou o desenvolvimento do estudo e participou da redação do artigo. 


\section{Referências}

1. Gostin LO, Hodge JG. Piercing the veil of secrecy in HIV/AIDS and other sexually transmitted diseases: theories of privacy and disclosure in partner notification. Duke J Gend Law Policy 1998; 5:9-88.

2. United Nations Joint Programme on HIV/AIDS. Opening up the HIV/AIDS epidemic. Guidance on encouraging beneficial disclosure, ethical partner counseling \& appropriate use of HIV case-reporting. Geneva: United Nations Joint Programme on HIV/AIDS; 2000.

3. United Nations Joint Programme on HIV/AIDS The role of name-based notification in public health and HIV surveillance. Geneva: United Nations Joint Programme on HIV/AIDS; 2000.

4. Cowan FM, French R, Johnson AM. The role and effectiveness of partner notification in STD control: a review. Genitourin Med 1996; 72:247-52.

5. Programa Nacional de DST e Aids, Secretaria de Vigilância de Saúde, Ministério da Saúde. Manual de controle das doenças sexualmente transmissíveis. $3^{a}$ Ed. Brasília: Ministério da Saúde; 1999.

6. Programa Nacional de DST e Aids, Secretaria de Vigilância de Saúde, Ministério da Saúde. Manual de controle das doenças sexualmente transmissíveis. $4^{\mathrm{a}}$ Ed. Brasília: Ministério da Saúde; 2006.

7. Minayo MCS. O desafio do conhecimento: pesquisa qualitativa em saúde. São Paulo: Editora Hucitec/Rio de Janeiro: ABRASCO; 1993.

8. Carlini-Cotrim B. Potencialidades da técnica qualitativa grupo focal em investigações sobre abuso de substâncias. Rev Saúde Pública 1996; 30:285-93.

9. Habermas J. Teoria de la acción comunicativa, I. 4 a Ed. Madrid: Editorial Taurus; 2003.

10. Habermas J. Pensamento pós-metafísico. 2a Ed. Rio de Janeiro: Tempo Brasileiro; 2002.

11. Repa L. A categoria do direito, no quadro da teoria da ação comunicativa. Prisma Jurídico 2006; 5:184-204.
12. Centers for Disease Control and Prevention. HIV/ PNSS operational guidance draft outline. Atlanta: Centers for Disease Control and Prevention; 1997.

13. Division of HIV/AIDS Prevention; National Centre for HIV, STD and TB Prevention, Centers for Disease Control and Prevention. Counseling and referral services - guidance. Atlanta: Centers for Disease Control and Prevention; 1998.

14. Silva NEK, Oliveira LA, Figueiredo WS, Landroni MA, Waldman CC, Ayres JRCM. Limites do trabalho multiprofissional: estudo de caso dos centros de referência para DST/Aids. Rev Saúde Pública 2002; 36(4 Suppl):108-16.

15. Peduzzi M, Palma JJL. A equipe de saúde. In: Mendes-Gonçalves RB, Nemes MIB, Schraiber LB, organizadores. Saúde do adulto: programas e ações na unidade de saúde. São Paulo: Hucitec; 1996. p. 234-50.

16. Paiva V. Cenas sexuais, roteiros de gênero e sujeito sexual. In: Barbosa RM, Parker R, organizadores. Sexualidades pelo avesso: direitos, identidades e poder. São Paulo: Editora 34/Rio de Janeiro: Instituto de Medicina Social, Universidade do Estado do Rio de Janeiro; 1999. p. 247-69.

17. Parker R, Agleton P. Estigma, discriminação e AIDS. Rio de Janeiro: Associação Brasileira Interdisciplinar de AIDS; 2002. (Coleção ABIA, Cidadania e Direitos, 1).

18. Goffman E. Estigma - notas sobre a manipulação da identidade deteriorada. 4ạ. Ed. Rio de Janeiro: Jorge Zahar Editor; 1982.

19. Ayres JRCM. O cuidado, os modos de ser (do) humano e as práticas de saúde. Saúde Soc 2004; 13:16-29.

Recebido em 16/Jan/2009

Versão final reapresentada em 12/Abr/2009 Aprovado em 27/Abr/2009 